\title{
Ultrasound assessment of the rectus femoris in patients with chronic obstructive pulmonary disease predicts poor exercise tolerance: an exploratory study
}

Mingming Deng ${ }^{1,2,3,4,5}$, Chaonan Liang ${ }^{6}$, Yan Yin ${ }^{6}$, Jun Shu' ${ }^{7}$ Xiaoming Zhou ${ }^{8}$, Qiuyue Wang ${ }^{6}$, Gang Hou ${ }^{1,2,3,4,5^{*}}$ and Chen Wang $1,2,3,4,5,9^{*}$

\begin{abstract}
Background: Reduced exercise tolerance is an important clinical feature of chronic obstructive pulmonary disease (COPD) and is associated with poor prognosis. The 6-min walk test (6MWT) is widely used to assess exercise capacity; however, it is not commonly administered in primary medical institutions because it requires a suitable site and professional training. Ultrasound has great potential for evaluating skeletal muscle dimensions in COPD. However, whether skeletal muscle ultrasound can predict impaired exercise tolerance is unclear.
\end{abstract}

Methods: The study included 154 stable patients with COPD, who were randomly divided into a development set and a validation set. The thickness $\left(\mathrm{RF}_{\text {thick }}\right)$ and cross-sectional area $\left(\mathrm{RF}_{\mathrm{csa}}\right)$ of the rectus femoris were measured using ultrasound. Standardized $R F_{\text {thick }}\left(S T D-R F_{\text {thick }}\right.$ ) and Standardized $R F_{\text {csa }}(S T D-R F c s a)$ were obtained via standardization of $\mathrm{RF}_{\text {thick }}$ and $\mathrm{RF}_{\text {csa }}$ by patients' height.

Results: Strong correlations were observed between the $6 \mathrm{MWD}$ and $\mathrm{RF}_{\text {thick }}(r=0.84, p<0.001)$ and between the $6 \mathrm{MWD}$ and $\mathrm{RF}_{\text {csa }}(r=0.81, p<0.001)$. In the development set, the optimal cut-off values for men and women for predicting poor exercise tolerance were $<3.098 \mathrm{~cm} / \mathrm{m}$ and $<3.319 \mathrm{~cm} / \mathrm{m}$ for STD-RF thick and $<4.052 \mathrm{~cm}^{2} / \mathrm{m}$ and $<4.366$ $\mathrm{cm}^{2} / \mathrm{m}$ for STD-RF $\mathrm{csa}_{\text {, }}$ respectively. In the validation set, the area under the curve (AUC) values for the prediction of a $6 \mathrm{MWD}<350$ by STD-RF thick and STD-RF csa $_{\text {were }} 0.881$ and 0.903 , respectively. Finally, the predictive efficacy of STD$\mathrm{RF}_{\text {thick }}$ (AUC: 0.922), STD-RF csa $_{\text {( }}$ (AUC: 0.904), and the derived nomogram model (AUC: 0.98) for exercise tolerance was superior to that of the sit-to-stand test and traditional clinical features.

Conclusions: Rectus femoris ultrasound has potential clinical application to predict impaired exercise tolerance in patients with COPD.

Keywords: COPD, Rectus femoris, Ultrasound, Exercise tolerance

*Correspondence: hougangcmu@163.com; cyh-birm@263.net ${ }^{1}$ Department of Pulmonary and Critical Care Medicine, Center of Respiratory Medicine, China-Japan Friendship Hospital, Beijing 100029, China

${ }^{9}$ Chinese Academy of Medical Sciences and Peking Union Medical College, Beijing 10029, China

Full list of author information is available at the end of the article

\section{Background}

Chronic obstructive pulmonary disease (COPD) is the third most common cause of death globally [1]. In China, COPD is the fifth leading cause of death, with a reported prevalence of $13.7 \%$ in people aged $\geq 40$ years $[2,3]$. Reduced exercise tolerance is one of the main clinical features of COPD, and it is associated with increased 
frequency of acute exacerbations and all-cause mortality $[4,5]$.

The six-minute walk test (6MWT) is a common method of assessing exercise tolerance. In the 6MWT, patients walk as far as possible along a minimally trafficked 30-m corridor for a period of $6 \mathrm{~min}[6,7]$. A $6 \mathrm{MWD}<350 \mathrm{~m}$ indicates impaired exercise tolerance and may predict a poor prognosis in COPD patients [8-10]. However, the $6 \mathrm{MWT}$ is difficult to administer in primary medical institutions because it requires an appropriate site (a 30-m flat course is required, and the layout of the track may influence the performance) $[11,12]$. Establishing a screening method that is highly accurate, simple, and can be performed in primary medical facilities is therefore important.

The mechanism underlying reduced exercise tolerance in COPD patients is multifactorial [13]. Increasing evidence indicates that skeletal muscle dysfunction limit the exercise ability of patients and lead to impaired exercise tolerance $[14,15]$. Identifying biomarkers related to skeletal muscle dysfunction may help predict exercise capacity in COPD patients. Recent study [16] has shown that the ultrasound assessment of the intercostal muscles can determine spirometry-related COPD severity. Ultrasound can also be used to estimate skeletal muscle dimensions of COPD patients $[17,18]$. However, whether skeletal muscle ultrasound can predict impaired exercise tolerance remains unclear.

In this prospective study, we hypothesized that ultrasound of the rectus femoris could predict poor exercise tolerance in patients with COPD. Our aim was to build a nomogram based on ultrasound of the rectus femoris to predict poor exercise tolerance in patients with COPD. First, we measured skeletal muscle dimensions in COPD patients by ultrasound and analysed the correlations of the 6MWD with the thickness and cross-sectional area. In addition, we determined the cut-off values for thickness and cross-sectional area of the rectus femoris to predict impaired exercise tolerance $(6 \mathrm{MWD}<350 \mathrm{~m})$. Finally, the nomogram model (combining traditional clinical features, STD-RF $F_{\text {thick}}$, and STD-RF $\mathrm{Fsa}_{\text {sa }}$ ) was found to improve the predictive ability of impaired exercise tolerance.

\section{Methods}

\section{Study design and patients}

A total of 154 COPD patients ( $\geq 40$ years old) from the First Hospital of China Medical University (Shenyang, China) were recruited for this prospective observational study between August 2018 and December 2019. The inclusion criterion was a diagnosis of stable COPD according to the Global Initiative for Chronic Obstructive Lung Disease (GOLD) criteria. The exclusion criteria were as follows: COPD exacerbation within the last 1 month; presence of severe cardiovascular disease or active lung disease; concomitant disease affecting the musculoskeletal system; long-term systemic steroid therapy; and inability to read or understand the informed consent documents. Clinical features, including age, sex, height, and weight, were obtained from medical records. The study was approved by the research ethics committees of the First Hospital of China Medical University, and written informed consent was obtained from all patients.

\section{Pulmonary function and assessment of modified British Medical Research Council (mMRC) scale and COPD Assessment Test (CAT)}

Spirometry measurements (pre-bronchodilator) were performed following the American Thoracic Society and the European Respiratory Society guidelines using a Jaeger MasterScreen system (Jaeger, Viasys Healthcare $\mathrm{GmbH}$, Hoechberg, Germany). Dyspnoea symptoms were measured using the Chinese version of the mMRC dyspnoea scale $[19,20]$, and health status was measured using the Chinese version of the CAT [21, 22].

\section{Quadriceps muscle strength (QMS)}

QMS was measured via a dynamometer (type: micro$\mathrm{FET}^{\mathrm{TM}}{ }^{\mathrm{T}}$; Hoggan, Salt Lake City, UT, USA) following the instructions in the manufacturer's manual and previous studies [23, 24]. The knee of the patient was flexed to $90^{\circ}$, and the dynamometer plate was placed. The anterior end of the dynamometer was located $5 \mathrm{~cm}$ proximal to the lateral malleolus on the anterior surface of the leg and perpendicular to the long axis of the tibia. The participant was then instructed to generate a maximal knee extension force to hold the line in the same position for a duration of $4 \mathrm{~s}$ by pushing against the dynamometer plate to which the investigator applied increasing force with no encouragement (see Additional file 2: Fig. S2). The participant was then asked to generate a maximal knee extension force to hold the line in the same position for a duration of $4 \mathrm{~s}$ by pushing against the dynamometer plate to which the investigator applied increasing force with no encouragement. The same steps were repeated twice, with an intervening interval of 30-60 s. The average value of the last two assessments for each lower limb was recorded as the maximum unilateral contraction force. Then, the average contraction force on both sides was used to obtain the QMS.

\section{Fat-free mass index (FFMI)}

The participant's body fat rate (BFR) was measured by a bioelectrical impedance meter (HBF-701, Omron, Japan). The FFMI was calculated as follows: 


$$
\text { FFMI }=\text { weight }(\mathrm{kg}) \times(1-\mathrm{BFR}) / \text { height }(\mathrm{m})^{2} .
$$

\section{Five-repetition sit-to-stand test (5STS) and the 30-s sit-to-stand test (30STS)}

The participant was seated on a chair that measured $48 \mathrm{~cm}$ high and had no armrests, with their feet on the ground, back supported by the back of the chair, and hands folded in front of their chest. After hearing the test start command, the participant was asked to stand up and sit down 5 times as quickly as possible; the time needed to complete the 5 repetitions was recorded. During the test, participants were instructed to keep their arms crossed on the chest, and to completely straight the knee joint when standing. The participant was given verbal encouragement during the test. The test was performed 3 times, with 1-min rest intervals. The average of 3 tests was recorded as the result. For the 30STS, the researcher recorded the number of times the participants stood up and sat down in $30 \mathrm{~s}$. The test was repeated three times, and the average value was recorded as the result.

\section{MWT}

According to the 2002 American Thoracic Society (ATS) guidelines [25], a closed, long, and straight 30-m indoor corridor was selected. The test method was explained to the patient before the test, and the patient was told to walk as much as possible. If they felt short of breath or experienced chest pain or dizziness, they were allowed to slow down or to stop to rest. If the above symptoms worsened and were not relieved after rest, the test was stopped immediately, and the patient was supervised by the experimenter and encouraged using standardized language. After $6 \mathrm{~min}$, the patient heard the experimenter say "time is up", which was their indication to stop. The test personnel recorded the distance travelled in metres.

\section{Measurements of the thickness and cross-sectional area of the rectus femoris}

Measurement of the quadriceps rectus femoris thickness and cross-sectional area was performed as in previous studies [26, 27]. Greyscale ultrasound was performed with an Aixplorer ultrasound scanning system (SuperSonic Imagine, Aix-en-Provence, France) with a 4- to $15-\mathrm{MHz}$ linear-array transducer. The width of linear-array transducer was $5 \mathrm{~cm}$. The entire cross-sectional image of the rectus femoris in all patients were visualized via Aixplorer ultrasound scanning system. Our ultrasonographers received formal training, and with $>10$ years of experience. The patient did not engage in strenuous exercise for $72 \mathrm{~h}$, rested quietly for $15 \mathrm{~min}$ and then laid on their back on the operating bed, relaxing all their muscles. The researchers set up a bracket to fix the ultrasound probe in place, thereby reducing muscle deformation due to external forces, and placed the ultrasound probe perpendicular to the patient's dominant leg. The transducer was positioned perpendicular to the long axis of the dominant leg (precisely at $3 / 5$ of the distance from the anterior superior iliac spine to the superior patellar border). This was the highest point in the thigh that the entire rectus femoris cross-section could be visualized in a single field in all subjects; other muscles of the quadriceps's group could not be encompassed in this manner. The scanning depth was set such that the femur could be detected for orientation. Gentle contractionrelaxation manoeuvres were employed to delineate the muscle septa prior to image acquisition. $\mathrm{RF}_{\text {thick }}$ and $\mathrm{RF}_{\text {csa }}$ were calculated after the inner echogenic line of the rectus femoris was outlined by a movable cursor on a frozen image (Fig. 1). $R F_{\text {thick }}$ and $R F_{\text {csa }}$ were recorded as the averages of three consecutive measurements within $10 \%$.

\section{Construction of the nomogram and decision curve analysis} A nomogram is an intuitive and effective method of displaying the results of a risk model. It was constructed using the R package "rms". Decision curve analysis was used to decide whether the predictive nomogram was clinically useful.

\section{Statistical analyses}

Statistical analyses were performed using SPSS 13.0 software (IBM, Armonk, NY, USA). Continuous variables are expressed as the median values and IQRs, as well as the minimum and maximum values. Spearman correlation coefficient analysis was used to compare the correlations of the $\mathrm{RF}_{\text {thick }}$ and $\mathrm{RF}_{\mathrm{csa}}$ with the clinical features of COPD

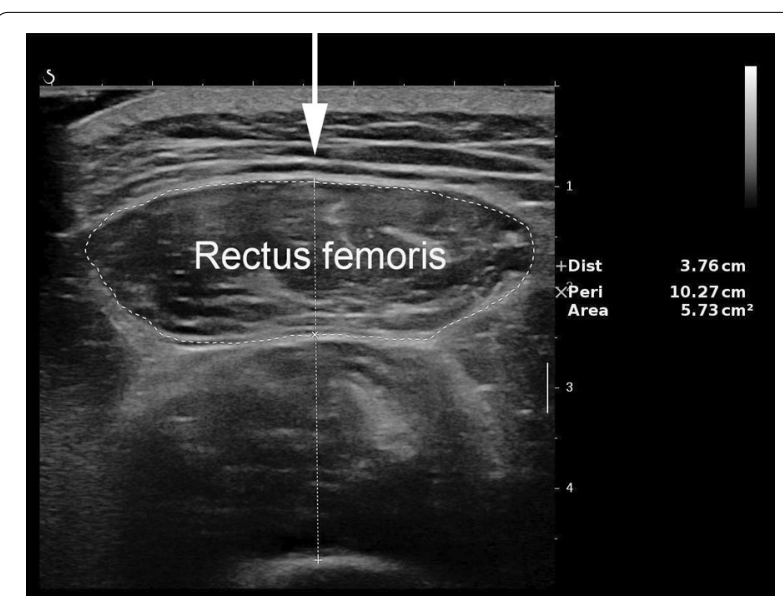

Fig. 1 Ultrasound of the rectus femoris. The arrow indicates the direction of the scan 
patients. The differences in the $\mathrm{RF}_{\text {thick }}$ and $R F_{\text {csa }}$ between men and women were determined using unpaired $t$ tests, and $\mathrm{p}$-values $<0.05$ were considered statistically significant. Receiver operating characteristic (ROC) curve analysis and the area under the curve (AUC) were used to determine the optimal cut-off values for STD-RF $F_{\text {thick}}$, STD- $\mathrm{RF}_{\mathrm{csa}}$ and the STST results for the prediction of a $6 \mathrm{MWD}<350 \mathrm{~m}$.

\section{Results}

\section{Patient characteristics}

A total of 154 patients were enrolled in the final analysis. The baseline characteristics of the patients are listed in Table 1. The range of $\mathrm{FEV}_{1} \%$ of our patients is 30.1$110.6 \%$. Our study population included patients of different severity, and it doesn't limit the external validity of the study.

\section{Relationships of quadriceps thickness $\left(\mathrm{RF}_{\text {thick }}\right)$ and quadriceps cross-sectional area $\left(\mathrm{RF}_{\mathrm{csa}}\right)$ with the clinical features of COPD patients}

The relationships of $R F_{\text {thick }}$ and $R F_{c s a}$ with the clinical features were analysed. As shown in Fig. 2A, the 6MWD

Table 1 Patient characteristics

\begin{tabular}{|c|c|}
\hline & Overall \\
\hline$n$ & 154 \\
\hline Age & $64(41-83)$ \\
\hline Sex/male (\%) & $108(70)$ \\
\hline $\mathrm{FEV}_{1}(\mathrm{~L})$ & $1.56(0.45-3.1)$ \\
\hline FEV ${ }_{1} \%$ pred & 59.35 (30.1-110.6) \\
\hline FVC $(\mathrm{L})$ & $2.80(0.92-5.21)$ \\
\hline FVC\% pred & $80.82(34.4-123.8)$ \\
\hline $\mathrm{FEV}_{1} / \mathrm{FVC}$ & $54.90(31-68.98)$ \\
\hline $\mathrm{RV}(\mathrm{L})$ & $4.06(1.34-7.31)$ \\
\hline TLC (L) & $6.44(3.52-9.84)$ \\
\hline RV/TLC (\%) & $73.69(31-242.4)$ \\
\hline BMI $\left(\mathrm{kg} / \mathrm{m}^{2}\right)$ & $23.92(11.3-37.3)$ \\
\hline FFMI $\left(\mathrm{kg} / \mathrm{m}^{2}\right)$ & $17.00(9.5-23.8)$ \\
\hline Height (cm) & $165.41(141-180)$ \\
\hline Weight (Kg) & $65.07(26.7-110.4)$ \\
\hline $\mathrm{mMRC}$ & $2(0-4)$ \\
\hline CAT & $15(0-37)$ \\
\hline $\mathrm{RF}_{\text {thick }}(\mathrm{cm})$ & $5.46(4.5-6.97)$ \\
\hline $\mathrm{RF}_{\mathrm{csa}}\left(\mathrm{cm}^{2}\right)$ & $7.05(6.01-8.28)$ \\
\hline $6 \mathrm{MWD}(\mathrm{m})$ & $369(108-554)$ \\
\hline QMS (kg) & $42.91(21.55-68.1)$ \\
\hline
\end{tabular}

FEV , Forced Expiratory Volume in the first second; $\mathrm{FEV}_{1} \%$ pred, $\mathrm{FEV}$ percentage predicted; FVC, forced vital capacity; FVC\% pred, FVC percentage predicted; RV residual volume; TLC, total lung capacity; BMI, body mass index; FFMI, fat-free mass index; CAT, COPD Assessment Test; 6MWD, 6-min walk distance; QMS, quadriceps muscle strength $(\mathrm{r}=0.870, p<0.001)$, forced expiratory volume in one second $\left(\mathrm{FEV}_{1}\right)(\mathrm{r}=0.418, p<0.001)$, forced vital capacity (FVC) $(\mathrm{r}=0.392, p<0.001)$, QMS $(\mathrm{r}=0.351, p<0.001)$ and percent predicted forced expiratory volume in one second $\left(\mathrm{FEV}_{1} \%\right.$ pred $)(\mathrm{r}=0.287, p<0.001)$ were positively correlated with $\mathrm{RF}_{\text {thick}}$; the CAT score $(\mathrm{r}=-0.206$, $p=0.013)$ and the mMRC score $(\mathrm{r}=-0.405, p<0.001)$ were negatively correlated with $\mathrm{RF}_{\text {thick }}$. The 6MWD $(\mathrm{r}=0.883, p<0.001), \mathrm{FEV}_{1}(\mathrm{r}=0.418, p<0.001), \mathrm{FVC}$ $(\mathrm{r}=0.399, p<0.001)$, QMS $(\mathrm{r}=0.388, p<0.001), \mathrm{FEV}_{1} \%$ pred $(\mathrm{r}=0.308, p<0.001)$, percent predicted forced vital capacity (FVC\%pred) $(\mathrm{r}=0.248, p=0.026)$, and $\mathrm{FEV}_{1} /$ $\mathrm{FVC}$ ratio $(\mathrm{r}=0.235, p=0.004)$ were positively correlated with $\mathrm{RF}_{\text {csa; }}$; the CAT score $(\mathrm{r}=-0.193, p=0.020)$ and mMRC score $(\mathrm{r}=-0.428, p<0.001)$ were negatively correlated with $R_{\text {csa }}$. The $6 \mathrm{MWD}$ showed significant strong positive correlations with $\mathrm{RF}_{\text {thick }}$ (Fig. 2B) and $\mathrm{RF}_{\mathrm{csa}}$ (Fig. 2C).

\section{Analysis and validation of STD- $\mathrm{RF}_{\text {thick }}$ and STD-RF csa $_{\text {. }}$ as predictors of poor exercise tolerance}

A total of 154 COPD patients were randomly assigned to a development set and a validation set at a ratio of $7: 3$ (Table 2). Because $\mathrm{RF}_{\text {csa }}$ and $\mathrm{RF}_{\text {thick }}$ differed between men and women (Additional file 1: Fig. S1), we performed ROC analysis in men and women separately to evaluate the predictive ability of $\mathrm{RF}_{\text {thick }}$ and $\mathrm{RF}_{\text {csa }}$ for poor exercise tolerance. And, Next, we standardized $R_{F}$ thick and $\mathrm{RF}_{\mathrm{csa}}$ by patients' height, and obtained STD- $\mathrm{RF}_{\text {thick }}$ and STD-RF ${ }_{\text {csa }}$. The ROC curves derived from the development set demonstrating the ability of skeletal muscle ultrasound to predict impaired exercise tolerance based on STD-RF thick $_{\text {and }}$ STD-RF $F_{\text {csa }}$ are shown in Fig. 3A. In male COPD patients, the sensitivity and specificity for predicting a poor $6 \mathrm{MWD}$ based on STD-RF thick were $91.3 \%$ and $88.24 \%$, respectively (the cut-off point was $3.098 \mathrm{~cm} / \mathrm{m}$ and the AUC was 0.951), and the sensitivity and specificity for predicting a poor 6MWD based on STD-RF csa were $86.96 \%$ and $88.24 \%$, respectively (the cutoff point was $4.052 \mathrm{~cm}^{2} / \mathrm{m}$ and the AUC value was 0.947 ). In female patients, the sensitivity and specificity for predicting a poor 6MWD based on STD-RF thick $_{\text {were }} 94.12 \%$ and $100 \%$, respectively (the cut-off point was $3.319 \mathrm{~cm} / \mathrm{m}$ and the AUC value was 0.971), and those for predicting a poor 6 MWD based on STD-RF csa $_{\text {were }}$ w4.12\% and $100 \%$, respectively (the cut-off point was $6.940 \mathrm{~cm}^{2} / \mathrm{m}$ and the AUC value was 0.963 ).

In the validation set (Fig. 3B), the sensitivity was $94.74 \%$ and the specificity was $81.48 \%$ for detecting a $6 \mathrm{MWD}<350 \mathrm{~m}$ with $\mathrm{STD}-\mathrm{RF}_{\text {thick }}$ (AUC value: 0.881 ), whereas the sensitivity and specificity for predicting a poor $6 \mathrm{MWD}$ based on STD-RF thick $_{\text {were }} 84.21 \%$ and $96.30 \%$, respectively (AUC value: 0.903 ). 


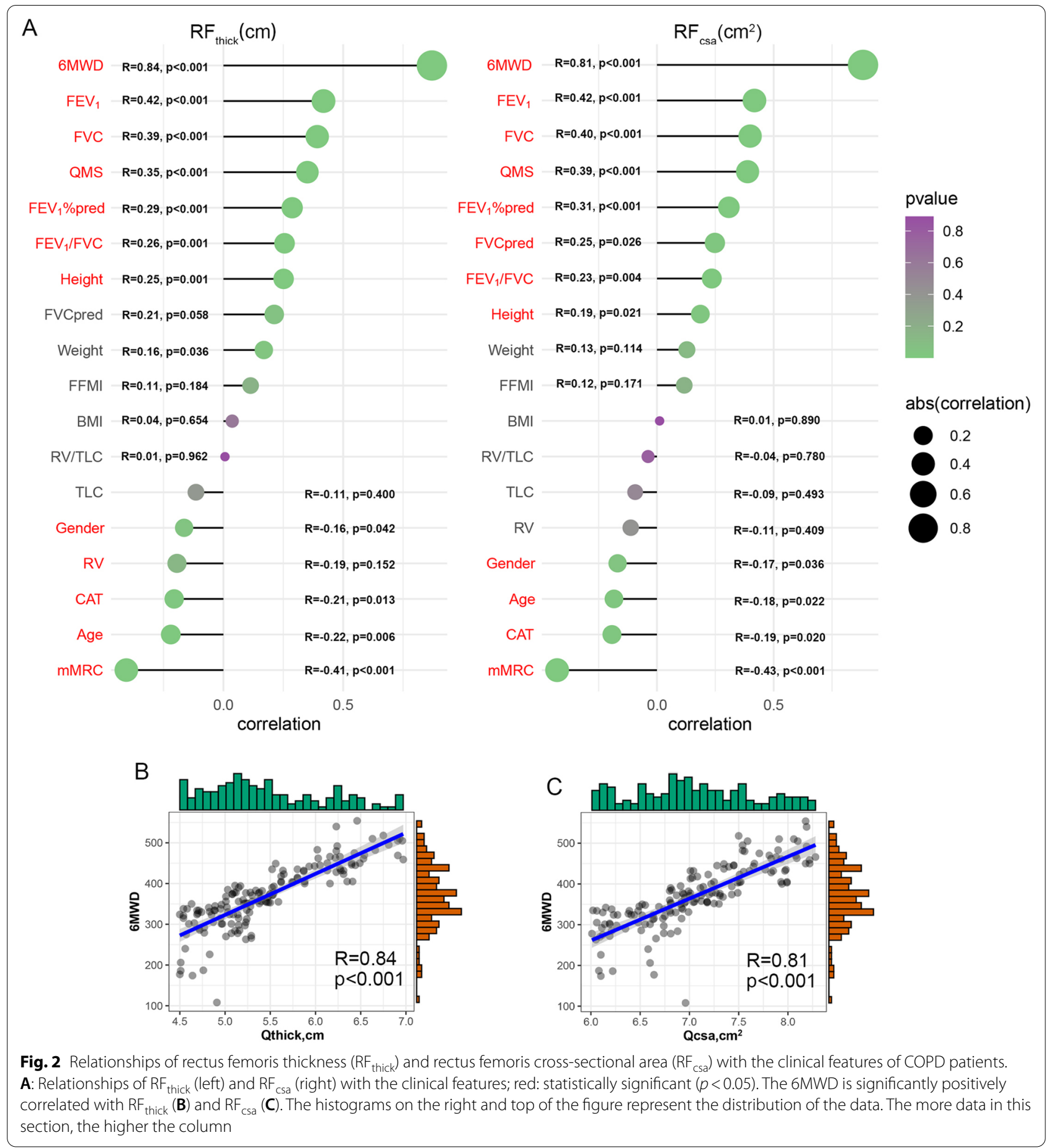

\section{Comparison of the predictive efficacy of skeletal muscle ultrasound and the STST}

The results from our group [24] and other studies [28-30] indicate that the STST can be used as a primary screening test to evaluate exercise tolerance in COPD patients. Therefore, we compared the efficacy of the STST to that of the STD-RF $F_{\text {thick }}$ and STD-RF $F_{\text {csa }}$ derived from skeletal muscle ultrasound in 154 COPD patients for predicting a poor 6MWD. As shown in Fig. 4, the AUC values for the 30STS score, 5STS score, STD-RF ${ }_{\text {csa }}$ and STD-RF $F_{\text {thick }}$ were 0.712, 0.724, 0.904, and 0.922, respectively. The sensitivities of the 30STS score, 5STS score, 
Table 2 Patient characteristics of development set and validation set

\begin{tabular}{|c|c|c|c|}
\hline & Development set & Validation set & $P$ value \\
\hline n & 108 & 46 & \\
\hline Age & $64(41-81)$ & $65(54-83)$ & 0.62 \\
\hline Sex/male (\%) & $75(69)$ & $33(72)$ & 0.926 \\
\hline $\mathrm{FEV}_{1}(\mathrm{~L})$ & $1.54(0.45-3.1)$ & $1.63(0.63-2.9)$ & 0.424 \\
\hline FEV ${ }_{1} \%$ pred & $58.12(15.8-99.5)$ & $62.38(30.1-110.6)$ & 0.263 \\
\hline $\mathrm{FVC}(\mathrm{L})$ & $2.79(0.98-5.21)$ & $2.82(0.92-4.75)$ & 0.852 \\
\hline FVC\% pred & $80.14(34.4-119.6)$ & $82.72(49.2-123.8)$ & 0.671 \\
\hline $\mathrm{FEV}_{1} / \mathrm{FVC}$ & $54.00(31-68.59)$ & $57.16(32-68.98)$ & 0.082 \\
\hline $\mathrm{RV}(\mathrm{L})$ & $4.12(1.97-7.31)$ & $3.90(1.34-6.43)$ & 0.608 \\
\hline TLC (L) & 6.55 (3.88-9.84) & $6.14(3.52-8.72)$ & 0.316 \\
\hline RV/TLC (\%) & 75.58 (39-242.4) & $68.53(31-149.2)$ & 0.522 \\
\hline $\mathrm{BMI}\left(\mathrm{kg} / \mathrm{m}^{2}\right)$ & $24.10(11.3-37.3)$ & $23.48(17.2-30)$ & 0.357 \\
\hline FFMI $\left(\mathrm{kg} / \mathrm{m}^{2}\right)$ & $17.09(9.5-23.8)$ & $16.78(11.8-19.3)$ & 0.461 \\
\hline Height (cm) & $165.42(141-180)$ & $165.40(147-177)$ & 0.991 \\
\hline Weight (Kg) & $65.84(26.7-110.4)$ & $63.26(40.2-90.3)$ & 0.323 \\
\hline $\mathrm{mMRC}$ & $2(0-4)$ & $2(0-4)$ & 0.599 \\
\hline CAT & $15(0-37)$ & $14(0-36)$ & 0.804 \\
\hline $\mathrm{RF}_{\text {thick }}(\mathrm{cm})$ & $5.48(4.51-6.97)$ & $5.41(4.5-6.96)$ & 0.515 \\
\hline $\mathrm{RF}_{\mathrm{csa}}\left(\mathrm{cm}^{2}\right)$ & $7.06(6.01-8.22)$ & $7.03(6.06-8.28)$ & 0.78 \\
\hline 6MWD (m) & $370.8(108-554)$ & $365.9(177-510)$ & 0.721 \\
\hline QMS (kg) & $42.89(21.55-68.1)$ & $42.94(24.2-65.05)$ & 0.986 \\
\hline
\end{tabular}

$\mathrm{FEV}_{1}$, Forced Expiratory Volume in the first second; $\mathrm{FEV} \%$ pred, $\mathrm{FEV}$ percentage predicted; FVC, forced vital capacity; FVC\% pred, FVC percentage predicted; RV, residual volume; TLC, total lung capacity; BMI, body mass index; FFMI, fat-free mass index; CAT, COPD Assessment Test; 6MWD, 6-min walk distance; QMS, quadriceps muscle strength

STD- $\mathrm{RF}_{\mathrm{csa}}$, and STD-RF $\mathrm{F}_{\text {thick }}$ were $70.97 \%, 82.86 \%, 96.61 \%$, and $77.97 \%$, respectively, whereas the specificities were $68.63 \%, 44.12 \%, 67.74 \%$, and $89.25 \%$, respectively. The above results showed that the levels of predictive power

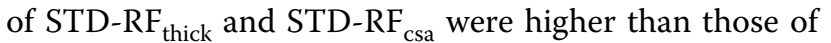
the STSTs.

\section{Construction of a nomogram to predict impaired exercise tolerance}

Exercise tolerance is affected by many factors, and has the complex mechanisms. Previous studies [31-33] have shown that Age, BMI, and pulmonary function are effective predictors of poor exercise tolerance in COPD. The Nomogram model could comprehensively incorporate the effects of diverse clinical factors. A nomogram model was constructed to predict impaired exercise tolerance $(6 \mathrm{MWD}<350 \mathrm{~m})$ in COPD patients based on traditional

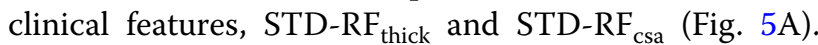
The performance of our model was confirmed via a calibration plot (Fig. 5B). Furthermore, the nomogram model had a higher AUC value than individual variables based on the results of the ROC analysis (Fig. 5C). Finally, the combined nomogram model had the highest efficacy for the prediction of a $6 \mathrm{MWD}<350 \mathrm{~m}$ according to decision curve analysis (Fig. 5D). These results confirmed the potential clinical value of our nomogram model.

\section{Discussion}

Ultrasound is a non-invasive technique that can be used to assess the physical condition of COPD patients and severity of COPD based on imaging of different areas, including the intercostal muscles and skeletal muscles $[34,35]$. In this study, the thickness and cross-sectional area of the rectus femoris determined via ultrasound were correlated with the clinical features of COPD patients, including pulmonary function, clinical symptoms, and exercise tolerance. STD-RF thick and STD-RF predicted poor exercise tolerance more effectively than the STSTs. A nomogram model constructed based on

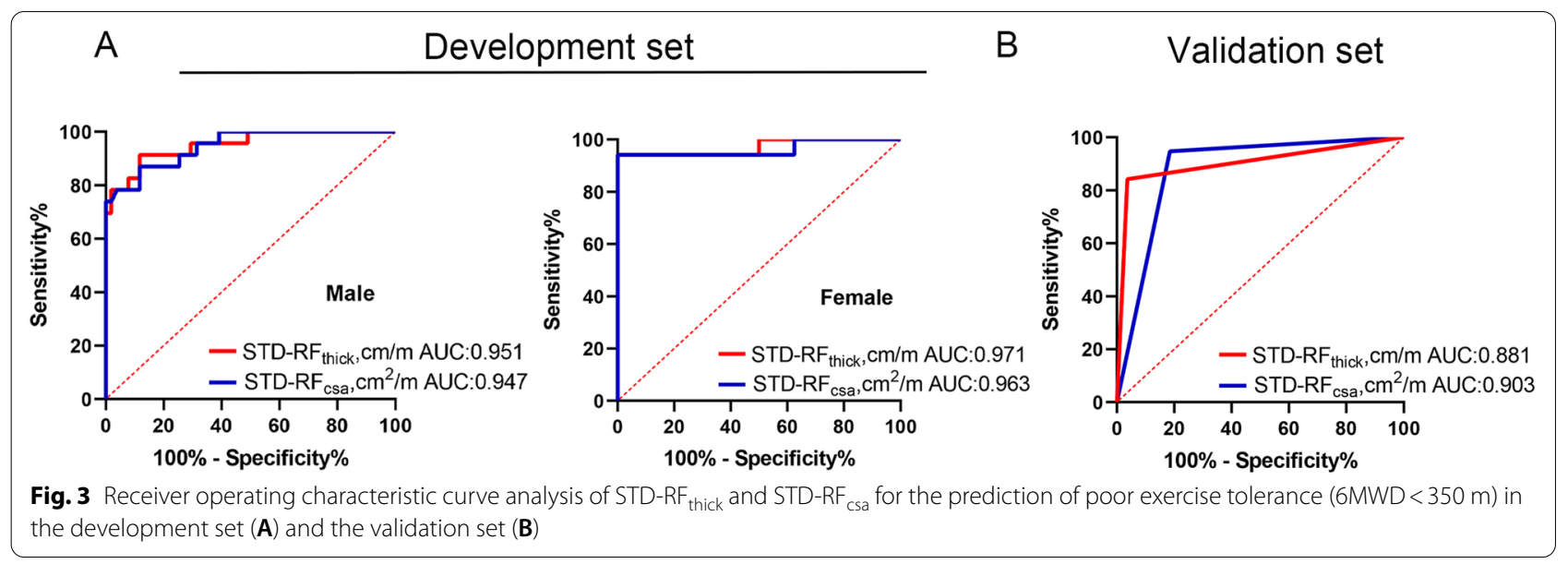




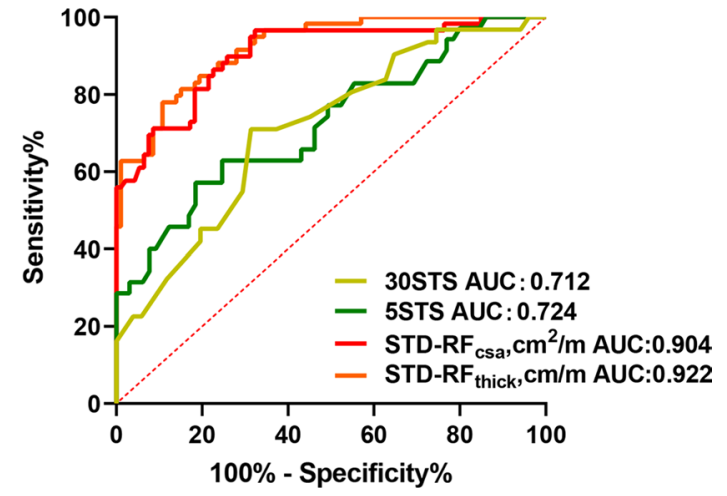

Fig. 4 Receiver operating characteristic curve analysis of STD-RF $F_{\text {thick' }}$ STD-RF csa' the 5STS, and the 30STS for the prediction of exercise tolerance $(6 \mathrm{MWD}<350 \mathrm{~m})$

$R F_{\text {thick }}, R F_{\text {csa }}$, and clinical features may help physicians with decision-making.

Skeletal muscle dysfunction, which is present in $1 / 3$ of COPD patients and is more common in patients with severe disease, can affect both ventilatory and nonventilatory muscles, leading to a poor prognosis $[36,37]$. Ultrasound is a promising tool for use in clinical practice to estimate skeletal muscle dimensions in COPD patients by measuring the thickness and crosssectional area of skeletal muscles $[17,18]$. We analysed a larger number of patients in this study than previous studies, and the results showed that $\mathrm{RF}_{\text {thick }}$ and $R F_{\text {csa }}$ were related to clinical features (including pulmonary function, symptoms, and exercise tolerance) in COPD patients. These results indicated that rectus femoris ultrasound may be a useful method of assessing disease severity in COPD patients.

In this study, results showed that STD-RF $F_{\text {thick }}$ and STD-RF $F_{\text {csa }}$ had the highest AUC values, sensitivities, and specificities, suggesting that they are more valuable predictors of a poor 6MWD than the 5STS and 30STS. Furthermore, the constructed nomogram model further improved the predictive ability to identify patients with impaired exercise tolerance (AUC: 0.98) and is much more visual.

The results of our study suggest that ultrasound measurements of the rectus femoris in patients with COPD have potential clinical value in the prediction of exercise limitation. However, we must note that ultrasound measurements provide only a partial quantification of muscle dimensions. 6MWD is a well-established and validated parameter in COPD patients, that is associated with daily activity, severity of disease, and prognosis [6]. Prediction of $6 \mathrm{MWD}<350 \mathrm{~m}$ through the quantification of muscle dimensions via ultrasound measurements still need more external data verification. In additional, sarcopenia, which includes both loss of muscle mass and function, has been recognized as a syndrome in patients with COPD [38, 39]. Ultrasound measurements of skeletal muscle may have potential value in the prediction of sarcopenia in these patients.

The present study has several limitations. 1, It should be considered as exploratory because participants were all from Northern China. Caution should be taken when extrapolating the clinical application of rectus femoris ultrasound to other ethnicities. 2, Most of our patients were male which reflects the higher prevalence of COPD in men (11.9\%) than in women (5.4\%) in China [3]. 3, Lack of a healthy control group. A previous study [18] indicates that mean $\mathrm{RF}_{\text {csa }}$ is reduced in patients with COPD by $25 \%$ of the mean value in healthy subjects. 4 , Whether ultrasound assessment of the rectus femoris could predict exercise tolerance in healthy subjects is unclear. One study [40] conducted in older heathy men found that a greater change in muscle width corresponded to faster walking speeds, suggesting a link between muscular dimensional changes and performance during dynamic activities. Based on these previous reports, future studies are needed to determine the clinical value of ultrasound assessment of the rectus femoris in healthy subjects. 5, Lack of the data of the reproducibility of the measures for different observers is the major limitation of this study. Previous study [41] about rectus femoris ultrasound measurements in 17 men with COPD showed that differences in cross-sectional area of the rectus recorded by two experienced operators in patients with COPD were not significant. Specifically, determination coefficient (0.99) and correlation coefficients (0.998) between cross-sectional area of the rectus recorded by two experienced operators in patients with COPD were high. And, the error of measurements $(0.06 \pm 0.03 \mathrm{~cm}, p=0.94)$ and percentage errors were small (1.4\%). Overall, that study [41] has determined the reproducibility and reliability of measurements obtained by experienced operators. Thus, the assessment of $\mathrm{RF}_{\text {thick }}$ and $\mathrm{RF}_{\text {csa }}$ by ultrasound also necessitates training and must to be performed by treating physicians or trained radiologists. Future studies are needed to further verify the reproducibility of ultrasound and the standardized operation of ultrasound. 6 , The study was limited to clinically stable patients with COPD. Whether the findings can be applied to patients with acute exacerbations of COPD and those undergoing pulmonary rehabilitation remains to be determined. These issues will be investigated in a future study. 


\section{A}

Points

$\begin{array}{lllllllllll}0 & 10 & 20 & 30 & 40 & 50 & 60 & 70 & 80 & 90 & 100\end{array}$

Age

Gender

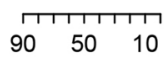

$\mathrm{FEV}_{1} / \mathrm{FVC}$

Male

BMI

75

\section{0}

STD-RF thick

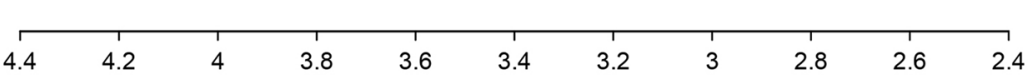

STD-RF csa

Total Points

\begin{tabular}{llllllllll}
\hline 5.2 & 5 & 4.8 & 4.6 & 4.4 & 4.2 & 4 & 3.8 & 3.6 & 3.4
\end{tabular}

$6 \mathrm{MWD}<350 \mathrm{~m}$

$\begin{array}{llllllllllll} & 20 & 40 & 60 & 80 & 100 & 120 & 140 & 160 & 180 & 200\end{array}$

B

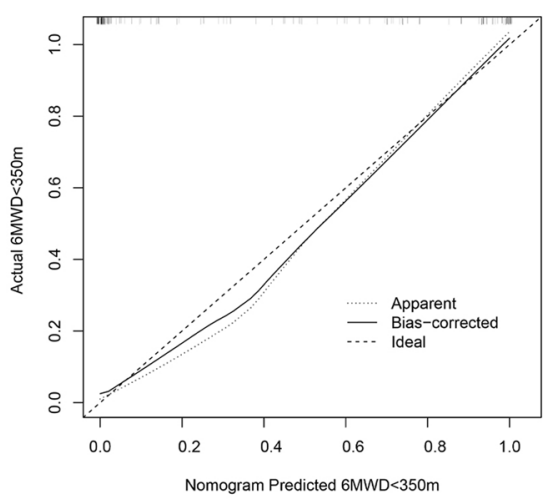

C

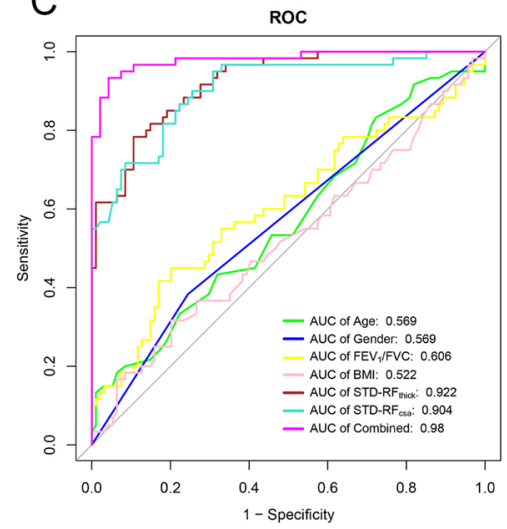

0.10 .50 .90 .99

Fig. 5 Construction of a nomogram model. A A nomogram was constructed to predict poor exercise tolerance $(6 \mathrm{MWD}<350 \mathrm{~m})$ in COPD patients. B Calibration curves for the nomogram for the prediction of poor exercise tolerance ( $6 \mathrm{MWD}<350 \mathrm{~m}$ ) in COPD patients. C ROC curve analysis showing that the highest AUC value corresponded to the nomogram model. D Decision curve analysis showing the net benefit of the nomogram model for the prediction of poor exercise tolerance $(6 \mathrm{MWD}<350 \mathrm{~m})$

\section{Conclusions}

Based on the measurement of ultrasound, thickness of the rectus femoris standardized by patients' height $(3.098 \mathrm{~cm} / \mathrm{m}$ for men, $3.319 \mathrm{~cm} / \mathrm{m}$ for women) and cross-sectional area of the rectus femoris standardized by patients' height $\left(4.052 \mathrm{~cm}^{2} / \mathrm{m}\right.$ for men, $4.366 \mathrm{~cm}^{2} / \mathrm{m}$ for women) have potential for the clinical assessment of exercise intolerance in patients with COPD.

\section{Abbreviations}

COPD: Chronic obstructive pulmonary disease; $6 \mathrm{MWT}$ : The 6-min walk test (6MWT); $\mathrm{RF}_{\text {thick: }}$ The thickness of the rectus femoris; $\mathrm{RF}_{\text {csa }}$ :The cross-sectional area of the rectus femoris; STD-RF thick: $_{\text {: }}$ Standardized the thickness of the rectus femoris; STD-RF ${ }_{\text {csa: }}$ Standardized the cross-sectional area of the rectus femoris; AUC: The area under the curve; 6MWD: 6-Min walk distance; mMRC: Modified British Medical Research Council; CAT: COPD Assessment Test; QMS: Quadriceps muscle strength; FFMI: Fat-free mass index; 5STS: Five-repetition sit-to-stand test; 30STS: The 30-s sit-to-stand test. 


\section{Supplementary Information}

The online version contains supplementary material available at https://doi. org/10.1186/s12890-021-01663-8.

Additional file 1: Fig. 1. The difference of ultrasound assessment of the rectus femoris in men and women. The $\mathrm{RF}_{\text {thick }}(\mathrm{A})$ and $\mathrm{RF}_{\text {csa }}(\mathrm{B})$ differed between men and women. ${ }^{*} P<0.05$.

Additional file 2: Fig. 2. The process of using the dynamometer. Measurement of quadriceps muscle strength via dynamometer.

\section{Acknowledgements}

Not applicable.

\section{Authors' contributions}

CW and GH designed the study. MD and GH wrote the manuscript. CL, YY, JS, $\mathrm{XZ}, \mathrm{QW}$ contributed to data collection and data analysis. All authors read and approved the final manuscript.

\section{Funding}

This research was supported by the Non-profit Central Research Institute Fund of Chinese Academy of Medical Sciences (No. 2020-PT320-001), National Natural Science Foundation of China (No. 81900040), Liaoning Education Ministry Supporting Foundation (No. QN2019014), and Liaoning Science and Technology Ministry Supporting Foundation (No.2019-ZD-0766).

\section{Availability of data and materials}

All data generated or analysed during this study are included in this published article.

\section{Declarations}

\section{Ethics approval and consent to participate}

All procedures performed in studies involving human participants were in accordance with the Declaration of Helsinki. And this study was approved by the research ethics committees of the First Hospital of China Medical University [No.2018-144-2]. Written informed consent was obtained from all participants in this study.

\section{Consent for publication}

Not applicable.

\section{Competing interests}

The authors have declared that no competing interest exists.

\section{Author details}

'Department of Pulmonary and Critical Care Medicine, Center of Respiratory Medicine, China-Japan Friendship Hospital, Beijing 100029, China. ${ }^{2}$ Graduate School of Peking Union Medical College, Chinese Academy of Medical Sciences, Peking Union Medical College, Beijing 100029, China. ${ }^{3}$ National Center for Respiratory Medicine, Beijing 100029, China. ${ }^{4}$ Institute of Respiratory Medicine, Chinese Academy of Medical Sciences, Beijing 100029, China. ${ }^{5}$ National Clinical Research Center for Respiratory Diseases, Beijing 100029, China. ${ }^{6}$ Department of Pulmonary and Critical Care Medicine, First Hospital of China Medical University, Shenyang 110001, China. ${ }^{\text {Institute of Clinical Medical }}$ Science, China-Japan Friendship Hospital, Beijing 100029, China. ${ }^{8}$ Department of Pulmonary and Critical Care Medicine, Fourth Hospital of China Medical University, Shenyang 110001, China. ${ }^{9}$ Chinese Academy of Medical Sciences and Peking Union Medical College, Beijing 10029, China.

Received: 27 April 2021 Accepted: 1 September 2021 Published online: 25 September 2021

\section{References}

1. Rabe KF, Watz H. Chronic obstructive pulmonary disease. Lancet (London, England). 2017;389(10082):1931-40.
2. Zhou M, Wang H, Zeng X, Yin P, Zhu J, Chen W, Li X, Wang L, Wang L, Liu $Y$, et al. Mortality, morbidity, and risk factors in China and its provinces, 1990-2017: a systematic analysis for the Global Burden of Disease Study 2017. Lancet (London, England). 2019;394(10204):1145-58.

3. Wang C, Xu J, Yang L, Xu Y, Zhang X, Bai C, Kang J, Ran P, Shen H, Wen F, et al. Prevalence and risk factors of chronic obstructive pulmonary disease in China (the China Pulmonary Health [CPH] study): a national crosssectional study. Lancet (London, England). 2018;391(10131):1706-17.

4. Riley CM, Sciurba FC. Diagnosis and outpatient management of chronic obstructive pulmonary disease: a review. JAMA. 2019;321(8):786-97.

5. Maltais F, Decramer M, Casaburi R, Barreiro E, Burelle Y, Debigaré R, Dekhuijzen PNR, Franssen F, Gayan-Ramirez G, Gea J, et al. An official American Thoracic Society/European Respiratory Society statement: update on limb muscle dysfunction in chronic obstructive pulmonary disease. Am J Respir Crit Care Med. 2014;189(9):e15-62.

6. Agarwala P, Salzman SH. Six-minute walk test: clinical role, technique, coding, and reimbursement. Chest. 2020;157(3):603-11.

7. Papaioannou Al, Loukides S, Gourgoulianis Kl, Kostikas K. Global assessment of the COPD patient: time to look beyond FEV1? Respir Med. 2009;103(5):650-60.

8. Puhan MA, Mador MJ, Held U, Goldstein R, Guyatt GH, Schünemann $\mathrm{HJ}$. Interpretation of treatment changes in 6-minute walk distance in patients with COPD. Eur Respir J. 2008;32(3):637-43.

9. Pinto-Plata VM, Cote C, Cabral H, Taylor J, Celli BR. The 6-min walk distance: change over time and value as a predictor of survival in severe COPD. Eur Respir J. 2004;23(1):28-33.

10. Casanova C, Cote CG, Marin JM, de Torres JP, Aguirre-Jaime A, Mendez R, Dordelly L, Celli BR. The 6-min walking distance: long-term follow up in patients with COPD. Eur Respir J. 2007;29(3):535-40.

11. Cote CG, Pinto-Plata V, Kasprzyk K, Dordelly LJ, Celli BR. The 6-min walk distance, peak oxygen uptake, and mortality in COPD. Chest. 2007;132(6):1778-85.

12. Sciurba F, Criner GJ, Lee SM, Mohsenifar Z, Shade D, Slivka W, Wise RA Six-minute walk distance in chronic obstructive pulmonary disease: reproducibility and effect of walking course layout and length. Am J Respir Crit Care Med. 2003;167(11):1522-7.

13. Di Marco F, Santus P, Sotgiu G, Blasi F, Centanni S. Does improving exercise capacity and daily activity represent the holistic perspective of a new COPD approach? COPD. 2015;12(5):575-81.

14. Sin DD, Man SFP. Skeletal muscle weakness, reduced exercise tolerance, and COPD: is systemic inflammation the missing link? Thorax. 2006:61(1):1-3.

15. Barreiro $E$, Gea J. Respiratory and limb muscle dysfunction in COPD. COPD. 2015;12(4):413-26.

16. Wallbridge P, Parry SM, Das S, Law C, Hammerschlag G, Irving L, Hew $M$, Steinfort D. Parasternal intercostal muscle ultrasound in chronic obstructive pulmonary disease correlates with spirometric severity. Sci Rep. 2018;8(1):15274

17. Ye $X$, Wang $M, X i a o H$. Echo intensity of the rectus femoris in stable COPD patients. Int J Chron Obstruct Pulmon Dis. 2017;12:3007-15.

18. Seymour JM, Ward K, Sidhu PS, Puthucheary Z, Steier J, Jolley CJ, Rafferty G, Polkey MI, Moxham J. Ultrasound measurement of rectus femoris cross-sectional area and the relationship with quadriceps strength in COPD. Thorax. 2009;64(5):418-23.

19. Bestall JC, Paul EA, Garrod R, Garnham R, Jones PW, Wedzicha JA. Usefulness of the Medical Research Council (MRC) dyspnoea scale as a measure of disability in patients with chronic obstructive pulmonary disease. Thorax. 1999;54(7):581-6.

20. Cui L, Ji X, Xie M, Dou S, Wang W, Xiao W. Role of inspiratory capacity on dyspnea evaluation in COPD with or without emphysematous lesions: a pilot study. Int J Chron Obstruct Pulmon Dis. 2017:12:2823-30.

21. Zhou Q-t, Mei J-j. He B, Huang S-g, Shi Y, Wen F-q, Zhao M-w: Chronic obstructive pulmonary disease assessment test score correlated with dyspnea score in a large sample of Chinese patients. Chin Med J. 2013;126(1):11-5.

22. Jones PW, Harding G, Berry P, Wiklund I, Chen WH, Kline Leidy N. Development and first validation of the COPD Assessment Test. Eur Respir J. 2009;34(3):648-54. 
23. O'Shea SD, Taylor NF, Paratz JD. Measuring muscle strength for people with chronic obstructive pulmonary disease: retest reliability of handheld dynamometry. Arch Phys Med Rehabil. 2007;88(1):32-6.

24. Zhang Q, Li Y-X, Li X-L, Yin Y, Li R-L, Qiao X, Li W, Ma H-F, Ma W-H, Han $Y-F$, et al. A comparative study of the five-repetition sit-to-stand test and the 30-second sit-to-stand test to assess exercise tolerance in COPD patients. Int J Chron Obstruct Pulmon Dis. 2018;13:2833-9.

25. ATS statement: guidelines for the six-minute walk test. Am J Respir Crit Care Med 2002, 166(1):111-117

26. Maynard-Paquette A-C, Poirier C, Chartrand-Lefebvre C, Dubé B-P. Ultrasound evaluation of the quadriceps muscle contractile index in patients with stable chronic obstructive pulmonary disease: relationships with clinical symptoms, disease severity and diaphragm contractility. Int J Chron Obstruct Pulmon Dis. 2020;15:79-88.

27. Shrikrishna D, Patel M, Tanner RJ, Seymour JM, Connolly BA, Puthucheary ZA, Walsh SLF, Bloch SA, Sidhu PS, Hart N, et al. Quadriceps wasting and physical inactivity in patients with COPD. Eur Respir J. 2012;40(5):1115-22.

28. Jones SE, Kon SSC, Canavan JL, Patel MS, Clark AL, Nolan CM, Polkey MI, Man WDC. The five-repetition sit-to-stand test as a functional outcome measure in COPD. Thorax. 2013:68(11):1015-20.

29. Bernabeu-Mora R, Medina-Mirapeix F, Llamazares-Herrán E, García-Guillamón G, Giménez-Giménez LM, Sánchez-Nieto JM. The Short Physical Performance Battery is a discriminative tool for identifying patients with COPD at risk of disability. Int J Chron Obstruct Pulmon Dis. 2015;10:2619-26

30. Morita AA, Bisca GW, Machado FVC, Hernandes NA, Pitta F, Probst VS. Best protocol for the sit-to-stand test in subjects with COPD. Respir Care. 2018:63(8):1040-9.

31. Schoos MM, Dalsgaard M, Kjærgaard J, Moesby D, Jensen SG, Steffensen I Iversen KK. Echocardiographic predictors of exercise capacity and mortality in chronic obstructive pulmonary disease. BMC Cardiovasc Disord. 2013;13:84

32. Díaz AA, Pinto-Plata V, Hernández C, Peña J, Ramos C, Díaz JC, Klaassen J, Patino CM, Saldías F, Díaz O. Emphysema and DLCO predict a clinically important difference for 6MWD decline in COPD. Respir Med. 2015;109(7):882-9.

33. Spiesshoefer J, Henke C, Kabitz HJ, Nofer JR, Mohr M, Evers G, Strecker J-K, Brix T, Randerath WJ, Herkenrath S, et al. Respiratory muscle and lung function in lung allograft recipients: association with exercise intolerance. Respiration Int Rev Thoracic Dis. 2020;99(5):398-408.

34. Radzina M, Biederer J. Ultrasonography of the Lung. Rofo. 2019;191(10):909-23.

35. Petousi N, Talbot NP, Pavord I, Robbins PA. Measuring lung function in airways diseases: current and emerging techniques. Thorax. 2019;74(8):797-805.

36. Maddocks M, Shrikrishna D, Vitoriano S, Natanek SA, Tanner RJ, Hart N, Kemp PR, Moxham J, Polkey MI, Hopkinson NS. Skeletal muscle adiposity is associated with physical activity, exercise capacity and fibre shift in COPD. Eur Respir J. 2014;44(5):1188-98.

37. Cruthirds CL, van der Meij BS, Wierzchowska-McNew A, Deutz NEP, Engelen MPKJ. Presence or absence of skeletal muscle dysfunction in chronic obstructive pulmonary disease is associated with distinct phenotypes. Arch Bronconeumol. 2020;57:264-72.

38. Cruz-Jentoft AJ, Sayer AA. Sarcopenia. Lancet (London, England). 2019;393(10191):2636-46

39. Sepúlveda-Loyola W, Osadnik C, Phu S, Morita AA, Duque G, Probst VS. Diagnosis, prevalence, and clinical impact of sarcopenia in COPD: a systematic review and meta-analysis. J Cachexia Sarcopenia Muscle. 2020;11(5):1164-76.

40. Giuliani HK, Shea NW, Gerstner GR, Mota JA, Blackburn JT, Ryan ED. The influence of age and obesity-altered muscle tissue composition on muscular dimensional changes: impact on strength and function. J Gerontol A Biol Sci Med Sci. 2020;75(12):2286-94.

41. Hammond K, Mampilly J, Laghi FA, Goyal A, Collins EG, McBurney C, Jubran A, Tobin MJ. Validity and reliability of rectus femoris ultrasound measurements: comparison of curved-array and linear-array transducers. J Rehabil Res Dev. 2014;51(7):1155-64.

\section{Publisher's Note}

Springer Nature remains neutral with regard to jurisdictional claims in published maps and institutional affiliations.
Ready to submit your research? Choose BMC and benefit from:

- fast, convenient online submission

- thorough peer review by experienced researchers in your field

- rapid publication on acceptance

- support for research data, including large and complex data types

- gold Open Access which fosters wider collaboration and increased citations

- maximum visibility for your research: over $100 \mathrm{M}$ website views per year

At $\mathrm{BMC}$, research is always in progress.

Learn more biomedcentral.com/submissions 